\title{
Legislation on euthanasia: recent developments in the Netherlands
}

\author{
J K M Gevers University of Amsterdam, the Netherlands
}

\section{Author's abstract}

Recently, new developments took place in the Dutch debate on the legislation of euthanasia. After a brief account of that debate, the article discusses a new government proposal for legislation in this field, which was submitted to the Dutch parliament in November 1991. This proposal relates not only to euthanasia but also to some other medical decisions concerning the end of life. The author concludes that, for several reasons, it is unsatisfactory.

Until now, in the Netherlands only the courts have left room for euthanasia (ie the deliberate termination of the life of a person on his or her request by another person). On the basis of these court decisions, euthanasia will usually not lead to prosecution and conviction if it is carried out by a doctor, rules of careful medical practice have been observed, the patient's request is persistent, his situation is desperate, his suffering is unbearable and there are no other solutions to his situation (1).

At the same time, euthanasia (and assistance in suicide) are still crimes under the penal code, even when a doctor is involved. This leaves patients and doctors with uncertainty. Court decisions are determined by the particular facts of the case and the courts have not succeeded in developing completely uniform standards as to what proper medical procedure and careful decision-making would entail.

Therefore, over the last decade the call for legislation has made itself felt. In this article, the recent government proposal in this field will be examined. After a brief review of the debate on the legalisation of euthanasia and the draft legislation proposed in the past, the main elements of the recent proposal will be discussed.

\section{The debate on the legalisation of euthanasia}

The question whether the existing legislation should be changed in order to liberalise euthanasia within certain well-defined limits, has been a matter of an extensive debate for several years. Among the opponents of

\section{Key words}

Euthanasia; law. legislation two groups can be distinguished. On the one hand there are those who are deeply convinced that euthanasia should never take place and that there can be no exception to the rule that a doctor should not terminate the life of a patient. Other opponents of legislation have no objections in principle to the court rulings, but they feel the complicated issues of medical decision-making at the end of life elude attempts at legislation. Such attempts would only result in political conflict or in unsatisfactory compromise. It would be better to leave the matter to the courts and to maintain the delicate balance between formal prohibition in the penal code and controlled acceptance in practice.

However, a substantial proportion of the population and a majority of politicians would seem to be in favour of legislation. Statutory regulation would not only have the advantage of providing more legal certainty, but also of making existing medical practice more subject to societal control. Legislation could even be an indispensable instrument in establishing such control. Apart from such practical considerations, many feel that the legislature should no longer evade questions of principle and should state clearly that in some instances the right to self-determination may take precedence over other concerns and justify a doctor in terminating the life of a patient on his request.

In 1982, a state commission on euthanasia was established to advise the government on its future policy with regard to legislation. In its report, published in 1985, the commission advocated modification of the penal code (2). In general, according to the commission, a person who intentionally ends the life of another person at the latter's explicit and earnest request should remain punishable, but an exception should be incorporated into the law for a doctor who does so with regard to a patient in a desperate, unbearable position which does not leave any prospects for change, provided that the doctor acts in accordance with careful medical practice. The commission further elaborated this last requirement proposing, inter alia, a mandatory consultation procedure. Before publication of the report, one of the non-denominational political parties had already introduced into parliament a bill which provided for legalisation of euthanasia in basically similar situations and with similar restrictions. That 
bill was adapted to the proposals of the state commission. In parliament, a majority seemed willing to support it, but the Christian Democratic party, which has dominated all government coalitions in the Netherlands for a long period of time, has so far been able to block parliamentary approval. As a matter of fact, the bill is still pending.

At the end of 1987, in order to meet the call for legislation at least to some extent, the government submitted its own proposal to parliament (3). That draft goes considerably less far than the aforementioned bill. Euthanasia would remain a crime, with no exception for doctors helping patients in desperate situations. A doctor could only be acquitted if he invoked a situation of emergency or force majeure and certain requirements concerning careful medical practice were complied with. It was proposed that these requirements would be incorporated in the Medical Practice Act. This compromise has been criticised as inconsistent by those in favour of the legalisation of euthanasia.

In 1989, before the government proposal had been debated in parliament, the government fell and new elections took place. In the subsequent negotiations on the formation of a new cabinet, the Christian Democrats and the Socialists agreed to make the adoption of legislation conditional on the outcome of a large confidential survey among medical practitioners. It was thought the survey would provide better insight into how decisions that influence the moment of death are made. In 1990, a committee of inquiry was appointed for this purpose. Before it published its report, however, another event took place.

Since euthanasia is not regarded as a cause of natural death, a doctor cannot write a death certificate, which means that the case will be reported by the medical examiner to the public prosecution. Although the number of cases reported to the authorities has been rising over the years, very often doctors disguised the facts and wrote a death certificate. They felt that they were being unjustly criminalised and exposed to the possibility of a not always discreet police investigation. The Dutch Medical Association exerted strong pressure on the Minister or Justice to agree to a less deterrent, and therefore more effective, procedure. Since November 1st 1990, a new procedure has been in force. After having received a complete written account from the doctor, the medical examiner reports to the district attorney who - when he has satisfied himself that the criteria laid down by the courts are met - will issue a certificate of no objection to burial or cremation, without further investigating the case. In approving this procedure the Dutch government took a small but significant step in the direction of not only tolerating, but also legalising, the practice of euthanasia.

\section{The new government proposal}

In September 1991, the committee of inquiry set up in 1990 to investigate the practice of euthanasia published its report, which included the results of a nationwide study not only on euthanasia, but also on other medical decisions concerning the end of life, such as withdrawal or withholding of treatment or the alleviation of pain in such dosages that the patient's life may be shortened (4). On the basis of the findings it is estimated that 1.8 per cent of deaths in the Netherlands are the result of euthanasia with some form of doctor involvement. In general practice euthanasia (and assisted suicide) would occur in about 2000 cases yearly. This is much lower than has been estimated previously in a number of publications in the Netherlands and abroad. The study also demonstrates that about two-thirds of the serious and persistent requests do not result in euthanasia because doctors can often offer alternatives.

One of the findings of the study is that in 0.8 per cent of all deaths lethal drugs were administered with the explicit intention of shortening the patient's life without the patient's persistent request. The study suggests that in the large majority of these cases death was imminent and that in almost all cases patients were suffering heavily. In most cases, patients were decisionally incapacitated at the time of the decision. In more than half of the cases the decision had been discussed with the patient when he or she was still competent, or the patient had in a previous phase of his or her illness expressed a wish for euthanasia should suffering become unbearable. These cases are at variance with the strict criteria for euthanasia set out by the courts, although one cannot exclude the possibility that a court would accept an appeal to a situation of emergency in circumstances of exceptional suffering even if there was no request from the patient.

In November 1991, after considering the results of the study and the recommendations of the report, the government sent a letter to parliament in which it set out its position on future legislation (5). Also, according to this new proposal, the penal code will not be changed. Termination of the life of a severely suffering patient on his request by a doctor will remain a crime. However, the notification procedure for cases of euthanasia which was agreed upon in 1990 (see above) will be laid down in regulations under the Burial Act and thereby acquire formal legal status. On the other hand, what careful medical practice in a case of euthanasia would require will not be included in the regulations; there will only be an appendix to the regulations with a list of questions (to be answered by the doctor) which relate to the requirements of careful medical practice.

As to other decisions concerning the end of life, the government agrees with the report of the committee of inquiry that most of them can be considered normal medical practice. This holds in particular for stopping a life-sustaining treatment that has become medically pointless, stopping a treatment or not starting a treatment on the patient's explicit request and alleviating pain with increasing dosages of opiates that are necessary to kill pain but which might shorten the 
patient's life. However, the government does not agree with the committee that also a decision to end the patient's life without his previous explicit request in a situation where death is imminent (because the patient has entered a process of irreversible loss of vital functions), can be considered normal medical practice. There should always be at least the possibility of judicial review of such a decision.

To increase the likelihood that such cases will be reported, it would be desirable to extend the notification procedure to all cases in which a doctor has actively shortened the life of a patient without the latter's explicit request. According to the government, each medical decision concerning the end of life is a unique one. The notification procedure would provide an appropriate framework for doctors to account for any decision involving either euthanasia or termination of life without request, although on the whole these two types of decisions are likely to be treated differently by the criminal justice system. After heated discussion, a majority of Parliament has approved this approach. In April 1992, the government withdrew its draft law of 1987 and submitted a bill to implement the new proposal (6).

\section{Discussion}

Several questions have been raised concerning the new proposal, not only within but also without Parliament (7). The Dutch Medical Association has welcomed the proposal as a whole, but it has also made a number of comments on it. Its main objection is that a doctor who acts in accordance with all the criteria developed by the courts will remain punishable, although it is very unlikely that he will be prosecuted (8).

In my view, the approach adopted by the government is not satisfactory. This holds both for euthanasia, and for shortening the life of a patient without his previous, unambiguous request.

As to euthanasia, the proposal would seem inconsistent. On the one hand, euthanasia will remain a crime, even if it is carried out by a doctor who complies with all the restrictions elaborated in the court rulings. On the other, the proposed modification of the Burial Act implies that the same doctor will not be prosecuted if he carefully commits that crime. Furthermore, if prosecuted, he can only invoke a situation of emergency or force majeure. The appeal to force majeure, however, has been developed in criminal law for exceptional situations, and not for situations which are foreseeable and occur on a regular basis. Finally, whereas according to its 1987 proposal at least the requirements for careful medical practice in the administration of euthanasia would have been laid down in statute law (the Medical Practice Act), the government now simply refrains from giving those requirements any formal legal status. This, however, makes its approach no less contradictory.

As to shortening the life of a patient without his request, the extension of the notification procedure to cases in which there is no previous, unambiguous request suggests that these cases can be dealt with on the same basis as cases of euthanasia. In this way, one creates the impression that shortening the life of a patient without request can be as legitimate as shortening his life on his explicit request. However, given the crucial role of the principle of selfdetermination or autonomy in the legal and ethical justification of euthanasia in the Netherlands, the distinction between the two types of cases remains essential and the question as to whether in a situation of unbearable suffering shortening human life without a request could ever be acceptable requires a separate, fundamental discussion. Furthermore, in inviting doctors to fill in the notification procedure forms, it is suggested that they may not be prosecuted after ending a patient's life without an explicit request. It is unlikely, however, that doctors will report these cases on a regular basis. In the past there have been a few court decisions in cases where the patient's wish to die was not established beyond doubt; the courts have been unanimous in convicting the doctors involved. Doctors have no reason to expect that the courts will handle cases without request in the same way as euthanasia cases. In fact, the courts have never developed standards for the first type of case and it is questionable whether they could or should do so.

On the whole, the government proposal is predominantly procedural in character. Most of all, it $\frac{0}{0}$ ? seems to be directed at increasing accountability and improving conditions of review. The basic, substantive questions are not answered in the proposed legislation. It is obvious, however, that if one wants to make laws on euthanasia, one has to face those questions and one cannot continue to leave them to the courts.

F KM Gevers is Professor of Health Law at the University of Amsterdam. He teaches in the Faculty of Law and in the Faculty of Medicine of that university.

\section{References}

(1) See for instance Leenen $\mathrm{H} \mathrm{J} \mathrm{J}$. Euthanasia, assistance to suicide and the law: developments in the Netherlands. Health policy 1987; 8: 197-206; Dying with dignity: developments in the field of euthanasia in the Netherlands. Medicine and law 1989; 8: 517-526.

(2) Final report of the Netherlands State Commission on Euthanasia: an English summary. Bioethics 1987; 1: 163174.

(3) Dutch Parliament, Second Chamber, 1987-1988, 20383: numbers 1-3.

(4) Medische beslissingen rond het levenseinde (Medical decisions concerning the end of life). Rapport van de Commissie onderzoek medische praktijk inzake euthanasie, SDU Uitgeverij, The Hague, 1991. The results of the study are presented in van der Maas $\mathrm{PJ}$ et al. Euthanasia and other medical decisions concerning the end of life. Lancet 1991; 338: 669-674.

(5) Dutch Parliament, Second Chamber, 1991-1992, 20383. number 14.

(6) Dutch Parliament, Second Chamber. 1991-1992, 22572: numbers 1-3.

(7) Leenen $\mathrm{H} \mathrm{J} J$. Het standpunt van het kabinet inzake regeling 
van euthanasie (The cabinet proposal concerning legislation on euthanasia). Tijdschrift voor Gezondheidsrecht. Fournal of health law 1992; 16: 2-8.

(8) Dutch Medical Association. Euthanasie: reactie hoofdbestuur KNMG op regeringsstandpunt (The cabinet proposal on euthanasia: a reaction of the Dutch Medical Association). Medisch contact 1991; 46: 15411543.

\section{Baby marrow: ethicists and privacy}

(Continued from page 127)

Clearly, however, as this paper shows, ethicists may publicly judge other ethicists.

\section{Acknowledgement}

I would like to thank the editor and an anonymous referee for many helpful suggestions.

Arthur Zucker is Associate Professor of Philosophy at
Ohio University, Athens, Ohio 45701, USA.

\section{References}

(1) Baby is conceived to save daughter. New York Times 1990 Feb 17: 10.

(2) Paton $\mathrm{H}$ J. The categorical imperative. London: Hutchinson and Co, 1947: 166.

(3) Wilkerson I. Court backs woman in pregnancy drug case. New York Times 1991 Apr 3: A15.

\section{News and notes}

\section{GMC statement about the treatment of patients on the basis of clinical need}

'The General Medical Council reiterates the principle that a doctor should always seek to give priority to the investigation and treatment of patients solely on clinical need.'

This statement forms part of guidance that the General Medical Council has decided to issue to all doctors following a debate on access to health care. It will be incorporated into the council's publication Professional Conduct and Discipline: Fitness to Practise, commonly referred to as the blue book.

The council also accepted a report from the Standards Committee concerning guidance to doctors on professional issues relating to access to health care and other related matters. This will be published shortly. 